\title{
Study of Supracondylar Fracture of Distal Humerus in Children and Its Management with Lateral K-Wire Fixation
}

\author{
Sapkota $K^{1,2^{*}}$ Shrestha $B^{2}$ \\ ${ }^{1}$ Department of Orthopaedics, Manipal College of Medical Science, Pokhara, Nepal, ${ }^{2}$ Department of Orthopaedics, \\ Fishtail Hospital and Research Centre, Pokhara, Nepal
}

\begin{abstract}
*Corresponding Author:
Dr. Krishna Sapkota,

Lecturer, Department Of Orthopaedics

Manipal College of Medical Science, Pokhara, Nepal

Fishtail Hospital and Research, Pokhara, Nepal

E-mail: krishapkota@gmail.com
\end{abstract}

\section{Citation}

Sapkota K, Shrestha B. Study of Supracondylar Fracture of Distal Humerus in Children and its Management With Lateral K- Wire Fixation Nepal Journal of Medical sciences 2014;3(1):38-43.

\begin{abstract}
Background:Supracondylar fracture is one of the common fractures in children. There are different methods of treatment. This study was undertaken to evaluate the results of lateral $\mathrm{k}$ wire fixation for the displaced supracondylar fracture of distal humerus in children.

Methods: There were 32 children with displaced Supracondylar fracture, treated with closed reduction and percutaneous lateral K-wires fixation. Clinical and radiological assessments were done and outcomes were assessed on basis of Flynn criteria and data were analyzed in SPSS 16. P value $<0.05$ was considered significant.

Result: The mean age of patients was $6.41 \pm 2.37$ with boys predominant. There were excellent result of $24(75 \%)$ good result $5(15 \%)$ regarding carrying angle and regarding range of motion 25 (78\%) excellent and $4(12 \%)$ good result. There were more than $90 \%$ patients with excellent to good result. Comparing the Baumann's angle intra-operatively and at the final follow up, there was no statistically significant differencewith $\mathrm{P}$ value $>0.05$.
\end{abstract}

Conclusion:Lateral pinning with 2 and if necessary $3 \mathrm{k}$ wires for proper stabilization and ideaconfiguration of divergent to hold medial and lateral column is the ideal treatment of supracondylar fracture without risk of iatrogenic nerve injury.

Keywords:Fracture distal humerus;lateral pinning; supracondylar fracture

\section{Background:}

A supracondylar humerus fracture is an extra-articular fracture of the distal humerus at the elbow that typically occurs in children between the ages of 5 and 9 years old. This injury accounts for around $70 \%$ of all elbow fractures in children and $3 \%$ to $7 \%$ of all fractures. ${ }^{1,2}$

There are many treatment modalities available with different outcomes but closed reduction and percutaneous lateral pinning is the treatment of choice in displaced Supracondylar fractures. Because of difficulty in maintaining reduction in plaster, operative reduction and pin fixation has become recommended practice. And this method has consistently given excellent results reported by various authors. ${ }^{1-3}$

There are numerous pinning techniques described in the 
literature. Different authors have used two crossed pins inserted from medial and lateral condyles. But it carries the risk of iatrogenic ulnar nerve palsy during insertion of medial pin with reported incidence of 4.3 times higher than with lateral pinning. ${ }^{3-6}$

However, controversy persists regarding whether medial and lateral pin fixation or divergent lateral pin fixation is satisfactory technique in terms of stability and iatrogenic ulnar nerve injury. ${ }^{6-8}$ Ideally medial and lateral pin fixation engage medial and lateral column at fracture site whereas lateral pin stabilizes lateral and central column. Medial and lateral pin fixation has been presumed to be more stable but it can cause iatrogenic ulnar nerve injury. However ideally placed divergent lateral pin, can provide the same stability like medial and lateral pin fixation, at the same time avoiding the possibility of iatrogenic ulnar nerve injury. ${ }^{9-12}$ The aim of this study was to evaluate the results of lateral Kirschnerwire fixation for the displaced supracondylar fracture of humerus in children.

\section{Methods:}

This was a prospective study conducted in Fishtail Hospital and Research Centre Pokhara, Nepal from 2011 January to 2012 December. Children with extension type supracondylar fracture of distal humerus presented in the hospital who met the inclusion criteria were included in the study. The inclusion and exclusion criteria used in the study were:

\section{Inclusion criteria}

All children with extension type II and type III supracondylar fracture of distal humerus presenting within 7 days of injury.

\section{Exclusion criteria}

Open fracture, presented more than 7 days, associated vascular injury and compartment syndrome, ipsilateral skeletal injury, fused distal humeral epiphysis, failed closed reduction (not accepted) and those which required open reduction.

A total of 32 patients who fulfilled the inclusion criteria underwent the procedure. All procedures were done by authors themselves. All the cases were done in intravenous anesthesia (IVA) (Ketamine). Preoperatively prophylactic antibiotic; Ceftriaxone was given 30 minutes before operation. Under IVA closed reduction was performed and the reduction was assessed with both Antero-posterior (AP) and lateral images using the image intensifier. Jones view as well as a 10-degree internal and external oblique AP was used to visualize the medial and lateral columns. Once anatomic reduction was confirmed, percutaneous lateral pin fixation was performed under radiographic control. The lateral elbow entry point was confirmed using the AP image. Suitablesizes of k-wire range from 1.8 to $2.5 \mathrm{~mm}$ were inserted laterally under image guidance. Most of the time $2 \mathrm{k}$-wireswereinserted as shown in figure 1. Where stability was in doubt we used $3 \mathrm{k}$ - wires from lateral side as shown in figure 2.

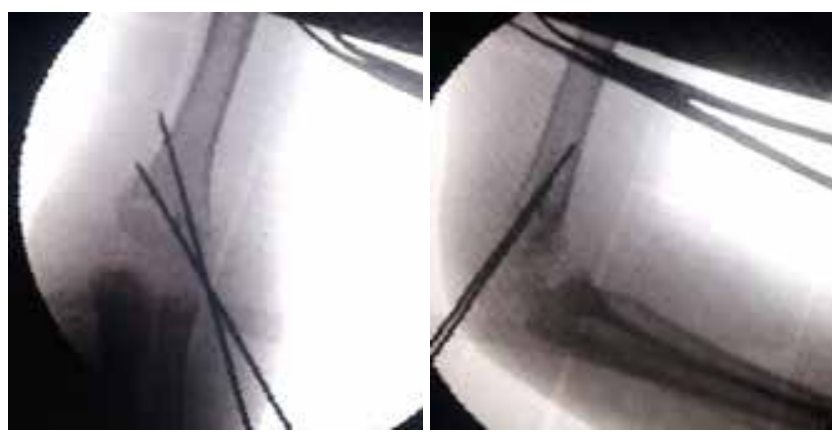

Fig 1:Type II supracondylar fracture stabilized with 2divergent lateral $\mathrm{k}$ wires

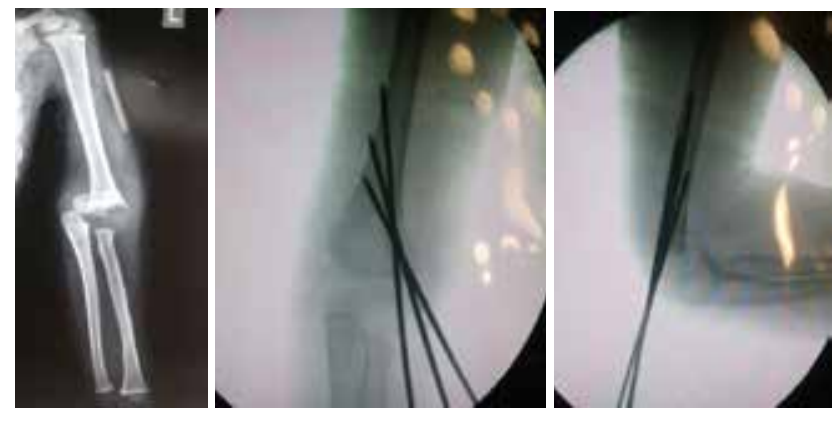

Fig 2: Type III Supracondylar \# stabilised with 3 lateral k-wires.

Stability was assessed in flexion and extension after putting two wires and a low threshold for third wire was maintained if stability was in doubt. If the ideal pin (divergent) configuration could not be achieved, then the other pin configurations were also accepted provided that fracture was stable.After 3 hours of completion of the procedure, neurovascular status was assessed and patients were discharged after 12 hoursafter re check of neurovascular status.

Follow Up:All patients were asked for follow up after $1^{\text {st }}$ and $2^{\text {nd }}$ week with check X-ray and then at 4 weeks for pins removal. Maintenance of fracture reduction was assessed by comparing perioperative radiographs with radiographs taken at the time of fracture union.

The Baumann's angle was compared between these radiographs to assess maintenance of reduction in coronal plane. A change in the relationship between the perioperative radiographs and those taken at the time of fracture-healing indicated a loss of reduction. Range of motion of elbow, 
neurological status and presence of deformity were assessed after 12 weeks of surgery. X-ray (AP views) of both the elbows were also taken at that time to compare ulno-humeral angle. Outcomes were analysis on basis of Flynn's criteria. ${ }^{4}$

Data collection and Statisticalanalysis:The data was collected in a predesigned proforma and analyzed using SPSS 16.0. The Student t test was used to determine the significance of any changes in the Baumann angle. The association between outcome and other variables were assessed. A p-value of 0.05 was considered significant.

\section{Results:}

A total of 32 patients were included in the study. The mean age of the patients was $6.41 \pm 2.37$ years (range $=3$ to 12 years, median 6 years). Nineteen patients were males and 13 were females.Most of them presented with fall from height (tree). Left elbow was involved in 22 patients. Type III fracture was commonest in our study. Twenty-one fractures were of type III and 11were of type IIB variety according to modified Gartland classification.Posteromedial displacement was the commonest type of displacement in type III fracture.The time interval between injury and operative treatment ranged from 4 hours to 36 hours but all the patients were managed within 12 hours of presentation to the hospital. Mean period of follow up in current study was 4.2 months (range $=3$ to 6 months). Though some patients reported late for final follow up; all patients were accounted for by 6 months period.

Among thirty two fractures, 20were stabilized with two lateral pins and 12 fractures with 3 lateral pins after closed reduction. All the 12 cases that stabilized with 3 pins were of type III. The outcome based on Flynn criteria is shown in table 1.

Table 1: Outcome based on Flynn criteria

\begin{tabular}{lcc}
\multicolumn{3}{c}{ Flynn's criteria } \\
\hline & $\begin{array}{c}\text { Cosmetic factor Carrying } \\
\text { angle loss (degrees) }\end{array}$ & $\begin{array}{c}\text { Functional factor Move- } \\
\text { ment loss (degrees) }\end{array}$ \\
Excellent & 24 & 25 \\
Good & 5 & 4 \\
Fair & 3 & 3 \\
Poor & 0 & 0 \\
\multicolumn{1}{c}{ Total } & $\mathbf{3 2}$ & $\mathbf{3 2}$
\end{tabular}

Table 2:Comparison of intraoperative Bauman angle and Bauman's angle at final follow up

\begin{tabular}{cccc}
$\begin{array}{c}\text { Intraoperative } \\
\text { Bauman angle } \\
\text { Mean (SD) }\end{array}$ & $\begin{array}{c}\text { postoperative } \\
\text { Bauman angle } \\
\text { Mean (SD) }\end{array}$ & $\begin{array}{c}\text { P } \\
\text { value }\end{array}$ & $\begin{array}{c}\mathbf{9 5 \%} \text { Con- } \\
\text { fidence } \\
\text { Interval }\end{array}$ \\
\hline $16.69(3.67)$ & $18.0(2.66)$ & 0.072 & $-2.75 ; 0.12$
\end{tabular}

Table 2 shows the comparison of intraoperative Bauman's angle with postoperative Baumann's angle. When intraoperative Baumann's angle and the Baumann's angle at the time of final follow up were compared using paired $\mathrm{T}$ test; there was no statistically significant difference ( $\mathrm{p}$ value $=0.072$ ). The mean difference was $-0.156^{\circ} \pm 0.987^{\circ}$. The greatest difference between perioperative and the final Baumann angle was $15^{\circ}$, seen in 2 patients with poor outcome(with marked cubitus varus deformity). However in patients with divergent pins the maximal change in Baumann angle was $3^{\circ}$. There was mean loss of $4.56^{\circ} \pm 3.72^{\circ}$ (range, $0^{\circ}$ to $15^{\circ}$ ) of carrying angle. The mean loss of motion was $4.81^{\circ} \pm 3.6^{\circ}$ (range, $0^{\circ}$ to $15^{\circ}$ ).

The mean duration of pin removal was $31.16 \pm 4.46$ days (range, 28 to 40 days). There were 5 cases with nerve palsy. Two radial and 2 anterior interosseous nerve palsy and one of median nerve palsy. All of them resolved completely by 3 months. Two patients developed Cubitus varus deformity with 15 degree angulations. Superficial pin track infection was detected in three of the patient at the time of pin removal. It subsided completely in a week with oral antibiotics and dressing. Other complications were not encountered.

\section{Discussion:}

The supracondylar fracture of the distal humerus is the commonest elbow injuries accounting for $75 \%$ of all elbow fractures with its peak incidence in 5 to 8 years of age. Our patients had a mean age of $6.41 \pm 2.37$ years with age group ranging from 3 to 12 years. Male children are more vulnerable to supracondylar fracture of humerus because they are more active, engage more in outdoor activities and are more prone to injury, was also reflected in our study.

Most of them had sustained the injury due to fall from height (tree) followed by fall on out stretched hands, as our hospital is in hilly station and most of the patients are from surrounding hilly station. Yadav et al in his study of total of 197 patients treated with closed reduction and percutaneous pinning have found mean age of incidence as 8 years, male predominance and left side as the common side of involvement which is similar to our study. ${ }^{13}$

Accurate reduction under image and proper stabilization provides excellent results. Lateral pin fixation in divergent manner is one of the treatment procedures which provide excellent result and is the accepted treatment of displaced supracondylar fractures of the humerus in children. ${ }^{1-5}$ The superiority of closed reduction and percutaneous lateral pinning over closed reduction and casting or open reduction has been described by many authors. ${ }^{1-5,14,15}$ Comparing the 


\section{Original Article | Sapkota K, et al. Study of Supracondylar Fracture of Distal}

result of our study to those of other where closed reduction and casting was used for the treatment of displaced supracondylar fractures, our result was better.

A biomechanical study had demonstrated that two divergent lateral-entry pins offer more stability in extension loading than do two crossed pins. ${ }^{10}$ It also showed that two divergent lateral-entry pins provide greater stability in varus and valgus loading than do two parallel lateral-entry pins. In that study, the parallel pins were close to each other and engaged only the lateral column, in contrast to the divergent pins, which were more widely separated at the fracture site and engaged both the medial and the lateral column. Another biomechanical study have shown that cross pinning are more resistant to torsional strength than lateral pinning and provide better stability but carries a greater risk of iatrogenic ulnar nerve injury. ${ }^{9}{ }^{11}$ Conversely, lateral $\mathrm{k}$ wire fixation has the advantage of avoiding ulnar nerve injury. ${ }^{6-8}$

It has been shown that crossed pins do provide more torsional stability than do two lateral pins but do not offer significantly more torsional stability than do three lateral pins. ${ }^{9-11}$ It has not been proved that the added stability of a medial pin is clinically necessary since, in young children, pin fixation is always augmented with immobilization in a splint or cast. ${ }^{9-11}$

On the basis of the results and their clinical experience, DL skaggs and coworkers are of the opinion that the most important factor for biomechanical stability is maximal separation of the pins at the fracture site; whether the pins happen to be parallel or divergent is less important. ${ }^{16} \mathrm{Bloom}$ et al. reported that three lateral divergent pins were equivalent to cross pin fixation and both of these constructs were stronger than two lateral divergent pins. ${ }^{12}$

In our study, all patients have satisfactory results functionally and cosmetically (75\% excellent, $15.63 \%$ good, $9.37 \%$ fair results) which corresponds to resultof the study reported by Cheng JC and coworkers. ${ }^{17}$ They evaluated 82 cases of supracondylar fractures treated with closed reduction and percutaneous K-wire fixation and had $80 \%$ of excellent or good outcome.

Sokak $\mathrm{S}$ et al believes that the most important factor for a good outcome in a patient with supracondylar fracture is adequate reduction rather than fixation. ${ }^{18} \mathrm{We}$ partly agree with him. The achievement of anatomical alignment in closed manipulation can be extremely difficult at times, forcing the surgeon to accept less than the ideal reduction. An improper reduction even precludes ideal pin placement.
In our study 12 patients had fixation with three lateral pins. Three pins were more often used in the typeIII fractures with posterolateral displacement. All the type II fractures had either excellent or good results. No loss of fixation was noted in patients with 3 pins, while all the patients (3/32) who had two non- divergent lateral pins, lost the fixation. The added stability given by a third pin and increased chance of making a divergent construct by a third pin may be the reasons for no displacement in fractures fixed with three pins. In our study there were 29 patients with ideal pin configuration. No loss of fixation was seen was noted in any of these 29 patients either in coronal or saggital plane.

The mean loss of carrying angle was $4.56^{\circ} \pm 3.72^{\circ}$ which does not differ much with the finding in a study by Foead et al. ${ }^{19}$ They had observed mean loss of $3.70^{\circ}$ of carrying angle in their study. Two patients in our study had cubitus varus deformity. Both of them had inadequate reduction and fixation. The three most common reasons for residual cubitus varus deformity mentioned in literatureare (1) the inability to interpret poor roentgenograms and thus acceptance of less than adequate reduction, (2) the inability to interpret good roentgenograms because of a lack of knowledge of the pathophysiology of the fracture, and (3) the loss of reduction. We believe that the reasons for cubitus varus deformity in two of our patients could be the same. ${ }^{1,2,4,9-11}$

Shoaib M et al reported excellent outcome in 65\%, good outcome in $20 \%$ and poor outcome in $15 \%$ patients in twenty patients treated with closed reduction and percutaneous pinning. ${ }^{20}$ Pirone et al in his study reported $78 \%$ excellent, $16 \%$ good, $1 \%$ fair and $5 \%$ poor result in patients treated with percutaneous pinning. This is similar to our study. ${ }^{21}$

There was no marked loss of range of motion of elbow in our study as compared to the study by Foead et al. ${ }^{19}$ In our study 25 patients had complete range of motion while the majority (7 patients) had some degree of loss of motion ranging from $5^{\circ}$ to $15^{\circ}$. Loss of extension was more frequently observed than loss of flexion.

The rate of iatrogenic ulnar nerve injury associated with cross medial and lateral pin has been reported to be from $0 \%$ to $6 \% .^{6-8}$ Others have reported that these injuries occur more commonly. ${ }^{24,25}$ In 1977 Arino et al. recommended two lateral pins in order to avoid ulnar nerve injury. ${ }^{22}$ Skaggs et al. reported that even making an incision over the medial epicondyle in an effort to ensure that the ulnar nerve is not directly injured does not guarantee protection of the nerve. ${ }^{16}$

Thus, even if direct injury to the ulnar nerve is avoided, just placing the pin over the medial epicondyle just adjacent to 
ulnar nerve can cause constriction of cubital tunnel. The lateral pinning avoids this complication.

The incidence of nerve injury was $15.6 \%$ in our study. The reported incidence of nerve injury associated with displaced supracondylar humerus fractures is between 10 and $20 \%$ in several studies. ${ }^{1,2}$ All the neurological injuries healed completely by 3 months. There were no cases with iatrogenic nerve injury in our study. The avoidance of ulnar nerve injury by lateral pins has been cited as the main advantage of lateral pins over crossed pins. ${ }^{1,2,14,18-20}$ Superficial pin track infection occurred in 3 of the cases in our study as compared to different rate and grade of pin tract infection in various studies $^{13,21}$ and all healed without complication.

\section{Conclusion:}

Closed reduction and percutaneous lateral K-wire fixation is the ideal treatment for displaced supracondylar fractures of humerus with good to excellent result. The use of only lateral divergent pins for fixation in 32 patients resulted in excellent to good results in over $90 \%$ of the patients; there was no iatrogenic nerve injury in any of the cases. Stable fixation can be achieved with two to three lateral pins engaging both medial and lateral columns with maximal separation of pins at fracture site. Insertion of a third pin usually increases the stability and increases the chance of making an ideal pin construct.

\section{Funding: None}

\section{Conflict of interest: None}

\section{References:}

1. Herring JA, eds. Fracture about the elbow. In: Tachdjian's Pediatric Orthopaedics. 3rd ed. Vol. 3. Philadelphia: W.B. Saunders 2002; 2139- 221.

2. Wilkins KE. Fractures and dislocations of the elbow region, in Rockwood CA Jr, Wilkins KE, King RE (eds): Fractures in Children, 3rd edition. Philadelphia: JB Lippincott; 1984:363-575.

3. Swenson AL. Treatment of supracondylar fractures of the humerus by Kirschner wire trans-fixation. J Bone Joint Surg Am 1948; 30:993-7.

4. Flynn JC, Matthews JG, Benoit RL. Blind pinning of displaced supracondylar fractures of the humerus in children. J Bone Joint Surg Am 1974: 56: 263-72.

5. Nacht JL, Eker ML, Chug SMK, et al. Supracondylar fracture of the humerus in children treated by closed reduction and percutaneous pinning. ClinOrthopRelat Res 1983;177:203.

6. Woratanarat $\mathrm{P}$, Angsanuntsukh $\mathrm{C}$, Rattanasiri S, et al.
Metanalysisof pinnngin Supracondylar fracture of humerusin children. J Orthop Trauma 2012;26:48-53. http://dx.doi.org/10.1097/BOT.0b013e3182143de0

7. Brown IC, Zinar DM. Traumatic and iatrogenic neurological complications after supracondylar humerus fractures in children. J PediatrOrthop 1995;15:440-3. http://dx.doi.org/10.1097/01241398-199507000-00005

8. Lyons JP, Ashley E, Hoffer MM. Ulnar nerve palsies after percutaneous cross-pinning of supracondylar fractures in children's elbows. J PediatrOrthop 1998; 18:43-5.

http://dx.doi.org/10.1097/00004694-199801000-00009

9. Larson L, Firoozbakhsh K, Passarelli R, et al. Biomechanical analysis of pinning techniques for pediatric supracondylar humerus fractures. J PediatrOrthop 2006;26:573-8 http://dx.doi.org/10.1097/01.bpo.0000230336.26652.1c

10. Lee SS, Mahar AT, Miesen D, et al. Displaced pediatric Supracondylar humerus fractures: biomechanical analysis of percutaneous pinning techniques. J PediatrOrthop2002; 22:440 -3.

http://dx.doi.org/10.1097/01241398-200207000-00005

11. Zionts LE, McKellop HA, Hathaway R. Torsional strength of pin configurations used to fix supracondylar fractures of the humerus in children. J Bone Joint Surg Am 1994;76:253 -6

12. Bloom T, Robertson C, Mahar A, et al. Comparison of Supracondylar humerus fracture pinning when the fracture is not anatomically reduced. Read at the Annual Meeting of the Pediatric Orthopaedic Society of North America; 2007 May 23-26; Hollywood, FL.

13. Yadav UB, Singhal R, Tonk G, et al. Crossed pin fixation in displaced supracondylar humerus fractures in children. Indian J Orthopaedics 2004;38:166-9.

14. Green NE. Fracture and Dislocation about the Elbow. In: Green NE, Swiontkowski MF (editors). Skeletal Trauma In Children. 2nd ed. Vol .3. Philadelphia: W.B. Saunders;1998.259- 317.

15. GartlandJJ.Managementofsupracondylarfracturesofthe humerus in children. SurgGynecolObstet 1959;109-54. 
Original Article | Sapkota K, et al. Study of Supracondylar Fracture of Distal

16. SkaggsDL, Hale JM, Basset J, et al. Operative Treatment of Supracondylar Fractures of the humerus in Children. J Bone Joint Surg Am 2001;83-A:735-40.

17. Cheng JC, Lam TP, Shen WY. Closed reduction and percutaneous pinning for type III displaced supracondylar fractures of the humerus in children.J Orthop Trauma1995;9:511-5.

http://dx.doi.org/10.1097/00005131-199509060-00009

18. Solak S, Aydin E. Comparison of two percutaneous pinning methods for the treatment of the pediatric type III supracondylar humerus fractures. J PediatrOrthop B 2003;12:346-9.

http://dx.doi.org/10.1097/00009957-200309000-00010

19. Foead A. Comparison of two methods of percutaneous pin fixation in displaced supracondylar fractures of the humerus in children.J OrthopSurg2004;12:76-82.

20. Shoaib M, Sultan S, Sahibzada SA, et al. Percutaneous pinning in displaced supracondylar fracture of humerus in children.J Ayub Med Coll Abbottabad. 2004; 16:48-50.

21. Pirone AM, Grahan HK, Krajbich JI. Management of displaced extension-type supracondylar fractures of the humerus in children. J Bone Joint Surg Am 1988;70A:641-50.

22. Arino VL, Llurch EE, Ramriez AM, et al. Percutaneous fixation of supracondylar fractures of the humerus in children. J Bone Joint Surg Am 1977;59:914-6. 